\title{
Don’t Stay Out Late! Mom, I'm Twenty-eight: Emerging Adults and Their Parents under One Roof
}

\author{
Asnat Dor ${ }^{1}$ \\ ${ }^{1}$ Department of education, Emek Yezreel Academic College, Israel \\ Correspondence: Asnat Dor, Department of education, Emek Yezreel Academic College, Emek Yezreel 19300, \\ Israel. Tel: 972-4-642-3561. E-mail: dorasnat@gmail.com
}

Received: December 7, 2012 Accepted: December 20, 2012 Available online: January 3, 2013

doi:10.11114/ijsss.v1i1.35

URL: http://dx.doi.org/10.11114/ijsss.v1i1.35

\begin{abstract}
This qualitative study focuses on Israeli parents of emerging adults who still live at home, and explores their feelings and thoughts of the benefits and difficulties of the situation. Semi-structured open interviews were conducted with 27 Jewish non-religious parents who have one child aged 21-30 living with them, who was the youngest in the family, and the last to leave home. Most participants expressed comfortable feelings toward their young adult child living at home, and also mentioned some difficulties and conflicts. The findings reveal that alongside the good feelings, parents face substantial challenges in living with their emerging adult offspring who are on an extended journey toward adulthood.
\end{abstract}

Keywords: adult development, family relation, parent attitudes, benefits, conflicts

\section{Introduction}

The current study is an attempt to reach an in-depth understanding of the point of view of Israeli parents of emerging adults who live at home. Emerging adults are young people, age 18-30, who are experiencing longer transition to adulthood - a period of search for self-identity, lack of stability, and a deferment of assuming long-term commitments. The emerging adult usually undergoes a variety of employment, love, and worldview experiences all of which delay marriage, parenthood, and professional and career decisions (Arnett, 2000; 2001; 2004; Juang \& Silbereisen, 2001; Shulman \& Ben-Artzi, 2003; Shulman, Feldman, Blatt, S, Coken \& Mahler, 2005).

\subsection{Relationships of Young Adults and Their Parents}

It is generally assumed that relationships of young adults and their parents change from an asymmetrical relationship regarding authority and influence in childhood and adolescence, to a more reciprocal, equal, and symmetrical relationship between adults (Buhl, 2009; Tanner, 2006). This transition represents a profound change in the family life, as it signifies a gradual shift in the way parents and young people view each other. Preferably, the parents learn to see their child as an autonomous individual (Aquilino, 2006), and no longer as a child who needs close attention, care and supervision. At the same time, young people learn to see their parents not just as their parents, but as persons, individuals with their own needs, weaknesses and life histories (Aquilino. 2006; Birditt, Fingerman, Lefkowitz, \& Kamp Dush, 2008; Vassallo, Smart, \& Price-Robertson, 2009; Youniss \& Smollar, 1985). When the parents reach old age, another change takes place, as the parents also receive support from their adult children (Buhl, 2009; Noack \& Buhl, 2004).

However, this gently shifting center of balance is not easily achieved. In some cases, the relationship is accompanied by ongoing conflicts between parents and their children (Clarke, Preston, Raksin, \& Bengtson, 1999), although these tend to decrease as the children enter adulthood, especially after they move out of the parents' home (Berman \& Sperling, 1991; Buhl, 2009). In cases where the young adults are financially dependent on the parents when they are considered "adults" in other respects, relationships may be tense (Aquilino, 2006; Vassallo et al., 2009).

\subsection{Emerging Adult's Residential Status}

Such tensions are especially prominent when young adults continue to live with their parents, an increasingly growing situation to a degree previously unknown (Arnett, 2001; 2004; Aquilino, 2006; Settersten \& Ray, 2010; 
Vassallo et al., 2009). Recent data reveal that over $50 \%$ of $18-24$ year olds in Europe and the United States are still living with their parents (Coleman \& Brooks, 2009; Kloep \& Hendry, 2010; U.S. Census Bureau, 2011), a situation caused by prolonged education, the high cost of living, or the convenience in delaying coping with economic issues. In some cases parental separation anxiety (Kins, Soenens \& Beyers, 2011), or disturbances in the process of separation-individuation (either by parents or adult children), can delay grown children from leaving the parents' house (Kins et al., 2011; Kloep \& Hendry, 2010). In Western society, leaving home has been traditionally understood as an important component of entering adulthood, yet recent research revealed that emerging adults' accommodation arrangements were not the core element of their self-developmental tasks (Kins et al., 2011; Yanir, 2007). According to Kins et al. (2011) it is important to pay attention to the reasons and the processes behind the emerging adult's residential status. Whether or not young adults live with their parents, is not a sole indication of their successful or lack of success in managing developmental tasks, and "there are cultural differences in expectations and traditions of young people leaving home and becoming independent" (Kloep \& Hendry, 2010, p. 818). However, whatever the reasons for such living arrangements, in a Western-oriented society these arrangements impact upon parent-child relationships as they are one prolong parental responsibilities later into life than in previous generations. Furstenberg (2010) sees a difference in parent-child relationships according to the child's life circumstances. Relationships between parents of children in their mid-twenties who are residing with the parents, are better if the children are studying, working, or searching for work, than if the children are having difficulties to find future direction toward independence. In all cases, mutual accommodation of parents and their children during the children's path toward adulthood requires adjusting to new patterns of interaction to meet the new demands of all members in the household (Yanir, 2007). At this stage, the parents (age 40-60), are also dealing with the challenges of midlife, which include assessment and evaluation of one's gains and losses (DeVries, Kerrick, \& Oetinger, 2007), physical decline, increased awareness of time limitation, and the recognition that not all personal goals would be reached. Added to these are illnesses or death of parents, friends, and relatives and changes in sexual drive and activity (Colarusso \& Nemiroff, 1987). The parents also have to combine between their own work and desired activities, the support they provide to their grown offspring and caring for elderly parents (Fingerman, Pitzer, Chan, Birditt, Franks , et al., 2011; Gautun \& Hagen, 2010).

\subsection{Israeli Emerging Adults}

Some researchers claim that middle-class Israeli Jewish emerging adults are very similar to middle-class people in North America (Mayseless \& Scharf, 2003; Schwartz, 1994; Shulman et al., 2005). Like their North American counterparts, Israeli emerging adults attribute importance to individualistic values, and tend to postpone the assumption of adult roles like marriage, parenthood, and vocational decisions. The rate of young adults who still live in their parents' house is similar to that of the United States, as $45 \%$ of the $20-30$ year olds in Israel still live with their parents who also give them a monthly allowance (Ben-Naftaly, 2008).

However, while the numbers may be similar, the reasons are different. At age 18, most Jewish Israeli men and women are drafted. During their two or more years of service, they are often exposed to high levels of responsibility, independence, and emotional maturity (Mayseless, 1993; Mayseless \& Scharf, 2003), all this while they continue to reside at home when not on base. However, exposure to a highly demanding and rigid authoritarian system, one that controls the life of the individual, may be a contributing factor to delaying full adulthood (Shulman, Blatt, \& Walsh, 2006). Thus, personal growth within the military may also increase dependent behavior and interfere with the natural experimentation processes of emerging adults (Gal, 1986; Mayseless \& Scharf, 2003; Shulman et al., 2006; Yerushalmi, 1997). Assuming adult responsibilities is further delayed by a custom that began developing in Israel in the mid-1980s. Upon discharge from the army, many young Israelis go on an extended (six months or more) journey, usually to the Far East or to South America, a journey that has come to "characterize part of the transition to adulthood among Israeli young people" (Shulman et al., 2006, p. 232). In addition, all discharged soldiers receive a one-time disposable deposit. This financial support is intended to help them finance their initial expenses in civilian life, and can be used for paying for higher education, purchasing a home, starting their own business, or marriage (Division for Discharged Soldiers, 2012).

\subsection{Research Scope and Objectives}

Kloep and Hendry (2010) and Vassallo et al. (2009), studied the parents' viewpoint of the transition of their emerging adult children toward adulthood. They found that not much research has been devoted to the effects of family transformations on parents. The focus is mostly on the views and experiences of the emerging adults (Cherlin, Scabini, \& Rossi, 1997; Galland, 1997), leaving much to be learned about parents' perceptions regarding their relations with their emerging adult children. According to Furstenberg (2010), researchers hardly 
know about how either young adults or their parents manage this longer period of co-residence and economic dependency, while they know quite a lot about the timing of home-leaving and its demography. Levitzki (2009) took this further in an examination of the experiences of Israeli parents and their perceptions of their parental role. This research revealed five internal dialectic dimensions, suggesting an ambivalence in the role perception of parents of adult children. The way parents in their 50s or 60s handle young people's prolonged dependency and the way they cope themselves with their children leaving home (Hendry \& Kloep, 2007), has an impact on their own psychological adjustment and their future relationships with their adult children (Kloep \& Hendry, 2010). It can be assumed that the macro social changes that affect the life trajectories of emerging adults, affect their parents' lives as well (Kloep \& Hendry, 2010). This study will focus on Israeli parents whose emerging adult children live with them, and will be an attempt to understand parents' feelings and thoughts about such living arrangements, and the benefits and difficulties of the situation. For that purpose, a three-question research protocol was developed, with the questions covering the way parents of emerging adults feel and handle this period in their lives.

\section{Method}

\subsection{Participant Characteristics}

For this qualitative study, we interviewed 27 Jewish non-religious parents (15 mothers, 12 fathers), who lived in the center of Israel, each representing a family. At the beginning of each interview, the parents were asked to give some background details regarding themselves and their emerging adult children.

The parents' age was 54-62 $(M=57.45, S D=3.4)$; all were married and had a child age 21-30 who were the youngest in the family and the last to leave home. Although in the research literature emerging adulthood begins at age 18, this study takes under consideration the special circumstances of the Israeli case - two to three years of compulsory military service, during which the young adults live at home when not on base. All the parents interviewed for this study lived in the center of Israel, were middle to middle-high socioeconomic class, and all had academic degrees (15 - BA, 10 - MA, 2 - PhD). None of them was dependent on their children because of a disability of some kind. Eight of the fathers worked full time, 3 worked part time, 1 was unemployed at the time of the interview. Of the mothers, 8 worked full time, 4 worked part time and 3 were unemployed. As for their professions, 10 were teachers, 5 hi-tech workers, 3 counselors and psychologists, 3 managers, and 3 secretaries.

The mean age of the children, all IDF veterans, was $23.7(S D=3.8)$. Seven had been discharged from the army within the year prior to the study (ages 21-22), the rests were 2-6 years after completing military service. During their military service, 13 lived at home on a daily basic (came home every evening), and 16 came home on weekends or when on leave. Six of them lived in a separate private living unit which was part of the parents' home. Twenty one of them had jobs (mostly part time jobs such as waiting tables, customer service, and salespeople in shops), 13 planned to pursue higher education and were preparing for the required psychometric exams, 15 were either planning on going on extended journey or were back from it. According to the parents, 7 of the 29 children had already made specific plans for the future, and these plans included moving out within a year. Three of these 29 who had moved out and lived in rented apartments, later returned to the parents' home due to financial reasons.

\subsection{Sampling Method, Procedure, and Data Collection}

The snowball method was used to reach participants for this study, beginning with five with whom the researcher was acquainted. These participants referred the researcher to others who met the criteria - having at least one child age 21-30 who lived at home and who was the youngest child in the family and last to leave the parents' home. Participation was voluntary. They were guaranteed confidentiality, and were also told that they could withdraw from the study at any stage. The one-on-one interviews took place in the participants' homes, at their convenience. Each interview was conducted by one of two graduate students of education, who were trained for this study and were supervised and guided by the researcher. The 45-70-minute interviews were audio recorded with participants' permission. Pseudonyms were assigned to maintain anonymity.

\subsection{Research Instrument and Data Analysis}

For this qualitative study, a semi-structured open interview was used, a tool that enables interviewees to expand and clarify their answers, and to give examples. The interviews followed the three-question research protocol designed for this study, and aimed to gain an in-depth look at parents' personal feelings and experience relating to their mutual accommodation with their emerging adult children. The questions were: (1) How would you generally describe your feelings regarding the fact that your son/daughter lives at home? (2) In your opinion, are there any difficulties you are coping with, that are related directly to the fact that your child is living at home? (3) 
Are there any benefits or advantages you experience that accompany his/her living at home?

Sabar Ben-Yehoshua's (1995) protocol for qualitative data analysis was used to analyze the interviews, with the aim of deriving distinct themes for each of the three questions. The analysis began with a search for systematic, repetitive, visible, and direct content. We later referred back to the content, sorting it by frequency of appearance and our interpretation of their significance to the interviewees, dividing the contents into groups and identifying prominent themes. Finally, we gave a title to each theme.

\section{Results}

The findings were analyzed according to their contents. For each interview question, the themes are listed in the order in which the questions were asked, and in some cases, parents gave more than one answer. Table 1 presents the themes identified in every question, by parent's gender.

Table 1 . Themes identified in every question, by parent's gender

\begin{tabular}{|c|c|c|c|c|}
\hline & & & \multicolumn{2}{|c|}{$N=27$} \\
\hline \multicolumn{2}{|l|}{ Question } & Themes & Mothers & Fathers \\
\hline \multirow{5}{*}{$\begin{array}{l}\text { Parents' } \\
\text { feeling }\end{array}$} & \multirow[b]{3}{*}{ Positive feelings } & Comfortable with it & $9(60 \%)$ & $8(66 \%)$ \\
\hline & & Staying young & $3(20 \%)$ & \\
\hline & & $\begin{array}{l}\text { Good relationship in } \\
\text { the family }\end{array}$ & 7 (47\%) & \\
\hline & \multirow[t]{2}{*}{ Negative feelings } & Worry & $7(47 \%)$ & \\
\hline & & Judgmental & $6(40 \%)$ & $4(33 \%)$ \\
\hline \multirow[b]{3}{*}{$\begin{array}{l}\text { Parents' } \\
\text { difficulties }\end{array}$} & \multirow[b]{3}{*}{ conflicts } & High financial costs & $5(33 \%)$ & 7 (58\%) \\
\hline & & Lack of privacy & $9(60 \%)$ & 4 (33\%) \\
\hline & & $\begin{array}{l}\text { Disapproval of the } \\
\text { child's habits }\end{array}$ & 7 (47\%) & $2(16 \%)$ \\
\hline \multirow[b]{3}{*}{ Parents' benefits } & \multirow{3}{*}{$\begin{array}{l}\text { Relationship and } \\
\text { some daily help }\end{array}$} & $\begin{array}{l}\text { Enjoying the } \\
\text { relationship }\end{array}$ & $7(47 \%)$ & $2(16 \%)$ \\
\hline & & Enjoying taking care & $3(20 \%)$ & \\
\hline & & $\begin{array}{l}\text { Being helped by the } \\
\text { child }\end{array}$ & $6(40 \%)$ & \\
\hline
\end{tabular}

Note: Most of the interviewees suggested more than one theme per question.

\subsection{Question 1. How Would You Generally Describe Your Feelings Regarding the Fact That Your Son/daughter} Lives at Home?

As seen in Table 1, two groups of themes were identified regarding this question: The first group of themes contained positive feelings: Comfortable with it (9 mothers, 8 fathers), Staying young (3 mothers), Good relationship in the family ( 7 mothers). The second group contained negative feelings: Worry (7 mothers) and Judgment (6 mothers, 4 fathers).

\subsubsection{Positive Feelings}

3.1.1.1 Comfortable. Some of the parents (9 mothers, 8 fathers) claimed that they are totally fine with their children living at home. They were aware of their children's future plans and claimed that staying at home at this point of life suites those plans. Anat, one of the mothers said:

It's perfectly fine with me. My daughter doesn't need to leave just yet. She's busy and studying for her psychometric exams. I hardly see her. If she leaves now to a place of her own it would be a total waste of money. When the time comes, it will happen.

Avi, one of the fathers, said: 
We have plenty of room, so why rush things? Our son needs to take his time and we are totally fine with it. In the future, he will organize his life and decide how to move on from here.

3.1.1.2 Staying young. Three mothers see the child's staying at home period as a good postponement of the empty nest stage, which will begin when the last child leaves home. As Nava, one of the mothers said:

It's nice to have her around. When she'll leave it will be just the two of us. This way I get to see other young people sometimes join their conversations. It keeps me young and gives me the opportunity to take care of her.

3.1.1.3 Good relationship in the family. Seven mothers claimed that it is good to know that their children feel comfortable enough to stay, and see it as a sign that the children feel comfortable in their relationships with their parents. Tal, one of the mothers said:

The fact that my son still lives here, must mean that he feels safe and comfortable. I don't judge him and don't nag him. He has all the privacy he needs, and I'm sure that the reason he's in no hurry to leave is the good atmosphere at home and the good relationship we share.

\subsubsection{Negative Feelings}

3.1.2.1 Worry. Almost a half of the mothers (7 mothers) in this study shared their worries regarding their child living at home. Among the issues they raised were their child's lack of direction, their own sense of self guilt, their child's lack of confidence to leave home or worrying about marriage. Worries were expressed by mothers only. Hadas, one of the mothers, said:

I don't pressure my daughter, but I'm not sure if I'm not doing something wrong that keeps her at home. Maybe she doesn't have enough confidence in herself, and she's afraid she won't manage living on her own.

Tal, another mother, said:

Our daughter is 24 . She leaves home to go to work and comes back. She hardly meets new people, hardly goes out for fun. I don't know what kind of chance she has to meet a partner, and meanwhile, time's going by.

3.1.2.2 Judgment. Some of the parents (6 mothers, 4 fathers) spoke about the significant inconvenience of having their children live at home. They were judgmental about the children who do not move themselves to cope with life's responsibilities as they coped, when they were young.

Shai, one of the fathers, said:

My daughter is 24, when I was her age I was already married. My wife and I rented an apartment and coped with everything, and it was good. I don't see this happening today. I don't see young people prepared to make an effort, and to live in a standard that is lower than they had in their parents' houses. They are too spoiled, getting everything for free so there is no reason for them to leave.

\subsection{Question 2. In Your Opinion, Are There Any Difficulties You Are Coping with That are Related Directly to the Fact That Your Child Is Living at Home?}

As seen in Table 1, The main theme regarding this question was conflicts. We identified conflicts over various topics, mostly -High expenses ( 5 mothers, 7 fathers), Lack of privacy (9 mothers, 4 fathers), and Disapproving of the child's habits ( 7 mothers, 2 fathers).

3.2.1 High expenses. Parents (5 mothers, 7 fathers) find themselves paying costs incurred by their adult child. They are worried both by the financial difficultly and by the lack of certainty as to the duration of the situation. Shalom, a father, shared these thoughts:

Having a child at this age, who spends quite a lot every month and doesn't earn his own money yet, is quite complicated. He likes to go out, invites his friends over sometimes, and this costs a lot. We have to face him about this but it $t$ is not easy for us to speak about money issues.

3.2.2 Lack of privacy. Some parents (9 mothers, 4 fathers) whose child returned home after having left, find it difficult to continue the routine they had established. For instance, parents who are used to watching a daily TV show, or eating at a certain hour, may discover that their plans are to be changed by the child who might have plans for the same time and space. Avner, one of the fathers, said:

Some evenings I get home from work and find my son hosting some friends in our living room, eating, smoking, listening to music. They all behave OK, but I have to find a place for myself. I can't just be 
wherever I want in my own house.

3.2.3 Disapproving of the child's habits. Some of the parents (7 mothers, 2 fathers) reported that they severely criticized their child for his or her lifestyle. A child who does not look for work, spends a lot of money, or leads an unhealthy life is a source of domestic conflict. Efrat, one of the mothers, shared her experience:

Our son came home after four years. Recently he asked us to come back home because it's too expensive for him out there. Of course we agreed, but it's not at all easy. I don't approve of his lifestyle. He goes out until the wee hours, sleeps almost all day, eats junk, and when I say something about it he says he's no longer a kid and he just wants to live his life. We argue a lot about all of this.

\subsection{Question 3. Are There Any Benefits or Advantages You Experience That Accompany His/her Living at Home?}

As can be seen in Table 1, three themes were identified regarding this question and were suggested by mothers only. The themes are Enjoying the relationship (7 mothers, 2 fathers), Enjoying taking care (3 mothers), and Being helped by the child (6 mothers).

3.3.1 Enjoying the relationship. The parents described pleasant feelings regarding their closeness to their child at this stage of life. Some claimed they enjoy seeing the child as a pleasant adult, a person whose company they can enjoy, especially when compared to the adolescent years. Two mothers mentioned that they feel that it is a chance to mend stressful relationship from the past, before the child leaves home.

Arik, father of a 22-year-old daughter, said:

I like the fact that she still lives with us, although I work very long hours and hardly at home. In weekends mostly, there is plenty of time for us to sit together, and catch up. She grew into a pleasant person, a thinking person, generous and funny. I'm enjoying every minute with her.

3.3.2 Enjoying taking care. Three mothers referred to the fact that while they know that their child will leave home and are prepared for it, they still enjoy the child being at home and letting the mother take care of him or her. Anat, one of the mothers said:

My son has been out of the army for only a year. His service was very difficult. I know he needs time for himself. In the meantime he's working and saving money. It is nice to have him back again, he lets me take care of him.

3.3.3 Being helped by the child. Six of the mothers referred to the help they enjoy getting from their children, as adults who can lend a hand with household chores. The help which they referred to was carrying groceries, or helping by visiting the grandparents.

Rachel, one of the mothers, said:

My mother is nearly 87, still lives in her old apartment and is quite capable to taking care of herself. Yet, I need to visit her every day and look after her in many ways (like taking her to the doctor, see that she has everything she needs, or just keeping her some company). I sometimes ask my daughter to help around and when she can she drives her grandmother or brings things to her house.

\subsection{Summary of the Research Findings}

Overall, most parents interviewed for this study expressed comfortable feelings toward their young adult child living at home. The mothers also perceive the situation as indicative of their good relation with the child and as a way to keep them feeling young. Mothers and fathers also expressed judgmental feelings, with the mothers adding worry to their judgment. When asked specifically about difficulties that accompany the child's living at home, all the parents expressed difficulties, while advantages were suggested mostly by mothers.

\section{Discussion}

The current study concentrates on parents of emerging adults who still live at home, examining the parents' feelings, attitudes, and ways of accommodating the situation. Emerging adulthood as a developmental stage has been of interest to researchers since the 1990s. However, studies have concentrated on the experiences of the emerging adults themselves, and little is known on parents' perceptions and coping with the transition of their children into adulthood (Cherlin et al., 1997; Galland, 1997). The goal in the current study was to focus on parents and to gain a deeper understanding of their perceptions and their coping mechanisms with the situation of having an adult child living at home.

Our findings indicate that, when asked about living with an emerging adult, parents' express complex feelings. Along with positive feelings and tolerance toward their children's long stay at home, some parents also feel uncomfortable. They lack privacy, and tend to criticize their children and conflict with them. 


\subsection{Parents' Advantages}

A look on the positive feelings parents expressed (Question 1) together with the advantages parents see in mutual cohabitation (Question 3) reveals that parents are generally tolerant of the period, especially in cases when the child actually has future plans, and is actively pursuing them. In other words, parents are more accepting and less judgmental of the children living at home if they believe that their children are moving in a positive direction toward achieving the developmental tasks of their age. This finding is consistent with Furstenberg (2010), who also found that mutual accommodation of parents and their mid-twenties children is better when the children are employed or studying, as opposed to those who show no move toward future independence. These positive attitudes can also reflect parents' role perception as guides, mentors, and emotional supporters of their children, as well as providers of financial assistance to their children in this period of time (Settersten \& Ray, 2010; Vassallo et al., 2009). It seems that with time, and as younger people tend to delay leaving their parents' home, parents have learned to accept and accommodate these changes, are aware of the fact that the current high cost of living demands financial assistance from families, and are willing to support their children in a variety of aspects (i.e. emotionally and financially). This support is given despite their awareness that when they were at their children's ages, they had been more autonomous financially and psychologically.

Findings in the current study indicate that the parents who have positive attitudes toward their children's prolonged stay at home and who feel comfortable with it, have succeeded in shaping a relationship that is more egalitarian, moving away from the parent-child pattern into a mutual relationship between adults (Aquilino, 2006). This kind of relationship probably enables the parents to enjoy the close presence of their young adult children who live at home, and to witness on a daily manner their growth into pleasant persons whose company they enjoy. Mothers in the current study expressed appreciation of the occasional household help that the children gave knowing that this mutual accommodation is temporary and seeing that the child has concrete plans for the near future, enables those parents to really enjoy the time with their emerging adult children, to feel positive about their presence and also to cherish their time together before future separation.

Some of the mothers in the current study took the fact that their child remained/returned home as a sign of a good home atmosphere, and they valued this view of their home life. The mothers also liked the situation which allowed them to continue taking care of their emerging adult children and caring for them, saying that having a child in the house keeps them feeling young.

These findings match the reports by Vassallo et al. (2009), who claimed that 20-30\% of the parents believe that physical care and emotional support continue to be part of their parental role. Galland (1997), also refers to the special way mothers perceive their role at this stage in their child's life, as providing emotional support, advice, and closeness especially to their daughters. In addition, difficulties to "let go" were also expressed by few mothers, perhaps due to separation anxiety and the fact that all the children in the families in this current research were the last to leave their parents' home (Kins et al., 2011; Kloep \& Hendry, 2010).

\subsection{Parents' Difficulties}

Along with the comfortable feelings and the enjoyment of the relationship that were expressed by a substantial number of parents in the current study, parents also spoke about difficulties (Question 3). In those families, the parents went through a period of adjustment to having their home for themselves intermittently when their children were in the army, and came home some weekends. This arrangement was changed again with the child returning home following their discharge from the army. The interviews reveal that having an emerging adult child live at home is especially challenging for the parents if they disapprove of the child's lifestyle or feel that he or she is not moving in an effective direction toward independence and adulthood. The parents reported a variety of conflicts they have had with their children (money issues, privacy issues, lifestyle, and every day habits). Such conflicts often force the parents to "take a deep breath" in order to cope with the situation, with possible effects on parents' psychological wellness. These effects are connected to issues such as separation anxiety, individuation processes and difficulties "to let go" (Kins et al., 2011; Klope \& Hendry, 2010; Levotzki, 2009).

The Israeli circumstances, which entail a mandatory 2-3 year military service beginning at age 18, create a unique situation. Parents had already undergone a gradual separation process while their children were in the army, and upon the children's discharge, they have to readjust to once again have their child live with them. This is especially relevant to those parents whose children came home from the army only on weekends (as opposed to the children who lived at home on a daily basic, during their military service). At this stage the children are a few years older and might have gone through some changes that parents view with disapproval.

Interestingly, few decades ago, social norms in Western countries called for children to leave home early, and 
parents felt uncomfortable if their children stayed at the parents' home beyond their mid-20s, because it probably meant that they had failed to socialize them (Schnaiberg \& Goldenberg, 1989). Nowadays, a child's late leaving home may be uncomfortable to parents due to different reasons, such as their own personal welfare and their own need of privacy. Settersten and Ray (2010) refer to the heavy burden that families bear in supporting young adult children through the extended process toward adulthood. Not all families can afford to support another adult at home, financially and emotionally. Because this is an individual process that an emerging adult is going through, and because it might take a few years, it is quite possible that social institutions will have to deal with this issue and not assume that parents can be responsible for their children for an unlimited period of time (Settersten \& Ray, 2010).

\subsection{Conclusions}

The current research leads to the conclusion that having an emerging adult child living at home is not a simple experience for parents: Even parents who were positive and happy about their children living at home, mentioned some difficulties that have to be considered, while other parents spoke about substantial difficulties that imply that the extended parental role is not clear and easy for parents at this stage of their lives.

\subsection{Research Limitations}

Although the findings of the current study contribute to a deeper acquaintance of parents of emerging adults, the limitations of this study must be borne in mind. First as a qualitative research, the extent to which we can generalize our findings to the entire Western population is limited. Second, it is quite possible that due to the sensitive topic of this study, not all parents felt comfortable enough to open themselves and maybe held back during the interviews. Third, we did not ask the parents about their perception of their children's level of maturity. According to Klope and Hendry (2010), these perceptions have a great deal to do with the parents' willingness to "let go". Fourth, the interviewees were all middle-class people, and it is likely that interviews with participants in different areas, and from different social backgrounds, might have led us to other results and insights. Additionally, because five of the initially interviewed families were the researcher's acquaintances, some bias may be present in their answers. Fifth, we need to recognize that the largely positive experience these parents were having could very well be the result of their being a select group; that is, they are all still in the co-residing situation. Families in which that arrangement was extremely conflicted and negative are not likely to continue it for long, thus we may not be picking them up in our sample. Nonetheless, we hope that the parents were honest in their answers to the interviewers' questions and their authentic voices are a main contribution of the current study. It suggested a significant opportunity for a deeper understanding of the experience of parents of emerging adults, in the extended journey toward their children's adulthood.

\section{References}

Aquilino, W. S. (2006). Family relationships and support systems in emerging adulthood. In J. J. Arnett \& J. L. Tanner (Eds.), Emerging adults in America: Coming of age in the 21st century (pp.193-210). Washington, DC: American Psychological Association. http://dx.doi.org/10.1037/11381-008

Arnett, J. J. (2000). Emerging adulthood: A theory of development from the late teens through the twenties. American Psychologist, 55, 469-480. http://dx.doi.org/10.1037//0003-066X.55.5.469

Arnett, J. J. (2001). Conceptions of the transition to adulthood: Perspectives from adolescence through midlife. Journal of Adult Development, 8, 133-143. http://dx.doi.org/10.1023/A:1026450103225

Arnett, J. J. (2004). Emerging adulthood: The winding road from the late teens through the twenties. New York: Oxford Press.

Ben- Naftaly, D. (2008). Comprehensive study of the lifestyle of 20-30 year olds in Israel. Globes, 19 May, 2008. Retrieved from http://www.globes.co.il/news/article.aspx?did=1000343267 (in Hebrew).

Berman, W. H., \& Sperling, M. B. (1991). Parental attachment and emotional distress in the transition to college. Journal of Youth and Adolescence, 20, 427-440. http://dx.doi.org/10.1007/BF01537184

Birditt, K. S., Fingerman, K. L., Lefkowitz, E. S., \& Kamp Dush, C. M. (2008). Parents perceived as peers: Filial maturity in adulthood. Journal of Adult Development, 15, 1-12. http://dx.doi.org/10.1007/s10804-007-9019-2

Buhl, H. M. (2007). Well-being and the child-parent relationship at the transition from university to working life. Journal of Adolescent Research, 22, 550-571. http://dx.doi.org/10.1177/0743558407305415

Cherlin, A. J., Scabini, E., \& Rossi, G. (1997). Still in the nest. Journal of Family Issues, 18, 572-575. http://dx.doi.org/10.1177/019251397018006001 
Clarke, E. J., Preston, M., Raksin, J., \& Bengtson, V. L. (1999). Types of conflicts and tensions between older parents and adult children. The Gerontologist, 39, 261-270. http://dx.doi.org/10.1093/geront/39.3.261

Colarusso, C. A., \& Nemiroff, R. A. (1987). Clinical implications of adult development theory. AM Journal Psychiatry, 144, 1263-1270. http://dx.doi.org/10.1177/000306518703500106

Coleman, J. C., \& Brooks, E (2009). Key data on adolescence. Brighton: Trust for the Study of Adolescence.

DeVries, H., Kerrick, S., \& Oetinger, M. (2007). Satisfactions and Regrets of Midlife Parents: A Qualitative Analysis. Journal of Adult Development, 14, 6-15. http://dx.doi.org/10.1007/s10804-007-9024-5

$\begin{array}{llll}\text { Division for } \quad \text { Discharged } & \text { Soldiers. } & \text { (2012). } & \text { Retrieved }\end{array}$ (http://www.hachvana.mod.gov.il/pages/hok/hok_pikadon_ishi.asp (in Hebrew).

Fingerman, K. L., Pitzer, L. M., Chan, W., Birditt, K., Franks, M. M., \& Zarit, S. (2011). Who Gets What and Why? Help middle-aged adults provide to parents and grown children. Journals Of Gerontology Series B: Psychological Sciences \& Social Sciences, 66B(1), 87-98.

Furstenberg Jr., F. F. (2010). On a new schedule: Transitions to adulthood and family change. Future of Children, 20(1), 67-87.

Gal, R. (1986). A portrait of the Israeli soldier. New York: Greenwood Press.

Galland, O. (1997). Leaving home and family relations in France. Journal of Family Issues, 18, 645-670. http://dx.doi.org/10.1177/019251397018006005

Gautun, H., \& Hagen, K. (2010). How do middle-aged employees combine work with caring for elderly parents? Community, Work \& Family, 13, 393-409. http://dx.doi.org/10.1080/13668800903360625

Hendry, L. B., \& Kloep, M. (2007). Conceptualizing emerging adulthood: Inspecting the emperor's new clothes? Child Development Perspectives, 1, 74-79. http://dx.doi.org/10.1111/j.1750-8606.2007.00017.x

Juang, L. P., \& Silbereisen, R. K. (2001). Family transition for young adult women in the context of a changed Germany: Timing, sequence and duration. American Behavioral Scientist, 44, 1899-1917. http://dx.doi.org/10.1177/00027640121958212

Kins, E., Soenens, B., \& Beyers, W. (2011). Why do they have to grow up so fast? Parental separation anxiety and emerging adults' pathology of separation-individuation. Journal of Clinical Psychology, 67, 647-664. http://dx.doi.org/10.1002/jclp.20786

Kloep, M., \& Hendry, L. B. (2010). Letting go or holding on? Parents' perceptions of their relationships with their children during emerging adulthood. British Journal of Developmental Psychology, 28, 817-834. http://dx.doi.org/10.1348/026151009X480581

Levitzki, N. (2009). Parenting of adult children in an Israeli sample: Parents are always parents. Journal of Family Psychology, 23, 226-235. http://dx.doi.org/10.1037/a0015218

Mayseless, O. (1993). Identity formation and emotional maturity of released soldiers in Israel. Tel Aviv: Israel Foundations Trustees.

Mayseless, O., \& Scharf, M. (2003). What does it mean to be an adult? The Israeli experience. New Directions for Child and Adolescent Development, 100, 5-20. http://dx.doi.org/10.1002/cd.71

Noack, P., \& Buhl, H. M. (2004). Child-parent relationships. In F. R. Lang \& K. L. Fingerman (Eds.), Growing together: Personal relationships across the lifespan (pp. 45-75). Cambridge, UK: University Press.

Sabar Ben-Yehoshua, N. (1995). The qualitative research. Tel Aviv: Modan (in Hebrew).

Schnaiberg, A., \& Goldenberg, S. (1989). From empty nest to crowded nest: The dynamics of incompletely-launched young adults. Social Problems, 36, 251-269. http://dx.doi.org/10.2307/800694

Schwartz, S. H. (1994). Beyond individualism/collectivism: New cultural dimensions of values. In U. Kim et al. (Eds.), Individualism and collectivism. Thousand Oaks, CA: Sage.

Settersten Jr., R. A., \& Ray, B. (2010). What's going on with young people today? The long and twisting path to adulthood. Future of Children, 20(1), 19-41.

Shulman, S., \& Ben-Artzi, E. (2003). Age-related differences in the transition from adolescence to adulthood and links with family relationships. Journal of Adult Development, 10, 217-226. http://dx.doi.org/10.1023/A:1026006025155

Shulman, S., Feldman, B., Blatt, S. J., Coken, O., \& Mahler, A. (2005). Emerging adulthood: Age-related tasks 
and underlying self process. Journal of Adolescence Research, 20, 577-603. http://dx.doi.org/10.1177/0743558405274913

Shulman, S., Blatt, S. J., \& Walsh, S. (2006). The extended journey and transition to adulthood: The case of Israeli backpackers. Journal of Youth Studies, 9, 231-246. http://dx.doi.org/10.1080/13676260600635672

Tanner, J. L. (2006). Recentering during emerging adulthood: A critical turning point in life span human development. In J. J. Arnett \& J. L. Tanner (Eds.), Emerging adults in America: Coming of age in the 21st century (pp. 21-55). Washington, DC: American Psychological Association. http://dx.doi.org/10.1037/11381-002

U.S. Census Bureau. (2011). More young adults are living in their parents' home. Census Bureau Reports. Retrieved from: http://www.census.gov/newsroom/releases/archives/families_households/cb11-183.html

Vassallo, S., Smart, D., \& Price-Robertson, R. (2009). The roles that parents play in the lives of their young adult children. Family Matters, 82, 8-14.

Yanir, I. (2007). Emerging adulthood in the family system: Developmental tasks and family dynamics. Unpublished PH.D dissertation. Haifa University, Israel (in Hebrew).

Yerushalmi, H. (1997). A psychoanalytic perspective on late adolescence in men in an Israeli combat unit. Psychoanalytic Psychology, 14, 113-127. http://dx.doi.org/10.1037//0736-9735.14.1.113

Youniss, J., \& Smollar, J. (1985). Adolescent relations with mothers, fathers, and friends. Chicago, IL: University Press. http://dx.doi.org/10.1177/0272431685051011

\section{(cc) EY}

This work is licensed under a Creative Commons Attribution 3.0 License. 